\title{
IN VITRO ANTIMICROBIAL AND ANTIOXIDANT ACTIVITIES OF A CRUDE EXTRACT AND FRACTIONS FROM Buddleja thyrsoides Lam. LEAVES
}

Janaina Dorneles Mahlke, Aline Augusti Boligon, Michel Mansur Machado, Tatiana Borba Spader, Sydney Hartz Alves, Thais do Canto-Dorow e Margareth Linde Athayde*

Curso de Farmácia, Centro de Ciências da Saúde, Universidade Federal de Santa Maria, Campus Camobi, 97105-900

Santa Maria - RS, Brasil

Recebido em 30/10/07; aceito em 16/9/08; publicado na web em 26/1/09

\begin{abstract}
Crude extract and fractions of Buddleja thyrsoides were investigated regarding antioxidant activities by DPPH, total phenolic contents by Folin-Ciocalteau and antimicrobial activity by the broth microdilution method. Total phenolics varied from $214.07 \pm 3.6$ to 438.4 $\pm 0.3 \mathrm{mg} \mathrm{g}^{-1}$. Crude extract, ethyl acetate, dichloromethane and butanolic fractions exhibited a weak scavenging activity $\left(\mathrm{SC}_{50}=186.04\right.$ $\pm 10.8,137.70 \pm 8.5,146.89 \pm 9.0$ and $165.71 \pm 3.2 \mu \mathrm{g} \mathrm{mL}^{-1}$, respectively). A correlation between the antioxidant activities and total phenolic contents could be shown $(\mathrm{r}=0.857, \mathrm{p}<0.01)$. The lowest value of MIC was observed with butanolic fraction against Saccharomyces cerevisiae (MIC and MFC at $62.5 \mu \mathrm{g} \mathrm{mL}^{-1}$ ). Dichloromethane and ethyl acetate fractions were effective against Staphylococcus aureus with MIC value at 250 and $500 \mu \mathrm{gLL}^{-1}$ respectively.
\end{abstract}

Keywords: Buddleja thyrsoides; antimicrobial; antioxidant activities.

\section{INTRODUCTION}

Buddleja is a genus with pan tropical distribution that occurs on South Asia, Africa and America. ${ }^{1}$ The flowers, leaves and roots of various species of Buddleja are used in traditional medicine in several parts of the world, evidencing the importance of this genus. ${ }^{2}$ Various bioactivities, including antimicrobial activity against Staphylococcus aureus, anti-rheumatic, anti-hepatotoxic, antifungal and antiprotozoal properties of crude extracts fractions or isolates compounds from this genus were reported. ${ }^{3}$ The leaves of a number of species of Buddleja are statement to be applied topically as a poultice or lotion for healing of wounds. ${ }^{4}$

Buddleja thyrsoides Lam., commonly known as "Barbasco" or "Cambará" belongs to the Scrophulariaceae family. It is a perennial herbaceous plant widely distributed in Southern of South America. In Brazilian folk medicine, leaves and flowers of this plant are taken by drinking an infusion made with hot water (tea) for the treatment of bronchitis and cough. ${ }^{5}$ The plant is still unknown on the chemical and pharmacology point of view, and no phytochemical study have been carried out on this species.

In the present study the crude extract and different $B$. thyrsoides extract partitions were evaluated regarding their antimicrobial activities, phenolic contents and free radical scavenger capacity. The antimicrobial properties of the crude extract and dichloromethane, ethyl acetate and $n$-butanolic fractions were tested against various microorganism including Gram-negative and Gram-positive bacteria, the yeasts Candida albicans and Candida glabrata, the fungi Saccharomyces cerevisae and the algae Prototheca zopfii using the broth microdilution method to achieve the Minimal Inhibition Concentration (MIC) and the Minimal Microbicidal Concentration (MMC), Minimal Fungicidal Concentration (MFC) and Minimal Algaecidal Concentration (MAC). The scavenging capacity of the crude extract and fractions of the plant were evaluated through the DPPH method and correlated to their total phenolic contents.

*e-mail: margareth@smail.ufsm.br

\section{EXPERIMENTAL}

\section{Instruments, chemicals and general procedures}

All the chemicals were of analytical grade. Solvents for the extractions, $L$-ascorbic and pyrogallic acids were purchased from Merck (Darmstadt, Germany). Folin-Ciocalteau phenol reagent $2 \mathrm{~N}$ and DPPH radical (1,1-diphenyl-2-picrylhydrazyl) were acquired from Sigma Chemical Co. (St. Louis, MO, USA). Spectrophotometric analysis was carried out on SHIMADZU-UV-1201, Kyoto, Japan. UV spectra of ethyl acetate and butanolic fractions (200 to $600 \mathrm{~nm}$ ) were recorded in $\mathrm{MeOH}$. Thin layer chromatography (TLC) were performed on silica gel $\mathrm{GF}_{254}$ (Merck) using the following eluents: EtOAc:MeOH:i-prOH:H $\mathrm{H}_{2} \mathrm{O}$ acetic $\operatorname{acid}(7: 1: 2.5: 0.2)$ and $\mathrm{MeOH}: \mathrm{H}_{2} \mathrm{O}: \mathrm{EtOAc}(16.5: 13.5: 100)$. Spots were detected under UV light and spraying with anisaldehyde: $\mathrm{H}_{2} \mathrm{SO}_{4}$ reagent and heat at $110^{\circ} \mathrm{C}$ for $10 \mathrm{~min}$. Authentic sample of verbascoside was obtained from Lippia alba.

\section{Plant material}

Leaves of Buddleja thyrsoides were harvested in São Luiz Gonzaga, State of Rio Grande do Sul, Brazil, on July of 2006. Samples of the collected material were identified by Botanist Dr. Thais do Canto-Dorow and archived as voucher specimens in the herbarium of Department of Biology at Federal University of Santa Maria by register number SMDB 10125.

\section{Extraction and partition of the leaves}

Air dried and powdered leaves of Buddleja thyrsoides (420 g) were extracted with ethanol $(70 \%)$ at room temperature for 7 days with daily agitation. After filtration, the extract was evaporated under reduced pressure to remove the ethanol in order to obtain a water suspension that was sequentially extracted at room temperature with dichloromethane, ethyl acetate and $n$-butanol (3x $100 \mathrm{~mL}$ for each solvent), yielding dichloromethane (13.06 g, 3.11\%), ethyl acetate (12.85 g, 3.06\%), and $n$-butanol (21.55 g, 5.13\%) soluble fractions 
respectively. A new amount of the same batch of plant material (100 g) was extracted with ethanol (70\%) at room temperature for seven days to afford the crude extract $(11.7 \mathrm{~g}, 11.7 \%)$ used in this study.

\section{Identification of verbascoside}

Approximately $1 \mathrm{~g}$ of $n$-butanol-soluble fraction was subject to chromatographic column (cc) over silica gel 60G (Merck) eluting with EtOAc:MeOH:i-prOH:H five fractions were collected (F1-F25) and analyzed by TLC using the same system described above. Analogous fractions were pooled together and a new sub-fraction 4 (F-4) was subject to a second $\mathrm{cc}$ in the same conditions described above to afford impure verbascoside (38.6 mg) as a main constituent. Identification was performed by direct comparison with authentic sample of verbascoside by TLC.

\section{Radical-scavenging activity - DPPH assay}

The antioxidant activity of the crude extract and fractions was evaluated by monitoring its ability in quenching the stable free radical DPPH, according to a slightly modified method. ${ }^{6}$ Spectrophotometric analysis was used to measure the free radical scavenging capacity (RSC) and to determine the scavenging concentration $\left(\mathrm{SC}_{50}\right)$ of the crude extract and fractions. The DPPH quenching ability was expressed as $\mathrm{SC}_{50}$ (the concentration required to inhibit radical formation by $50 \%)$. Six different ethanol dilutions of each fraction $(2.5 \mathrm{~mL})$, at $250,125,62.5,31.25,15.62$ and $7.81 \mu \mathrm{g} \mathrm{mL}^{-1}$ were mixed with $1.0 \mathrm{~mL}$ of a $0.3 \mathrm{mM}$ DPPH ethanol solution. Ethanol $(1.0 \mathrm{~mL})$ plus plant extract solution $(2.5 \mathrm{~mL})$ was used as a blank. The absorbance was measured at $518 \mathrm{~nm}$ by UV-VIS spectrophotometer after 30 min of reaction at room temperature. The radical was prepared daily and protected from light. Relative activities were calculated from the calibration curve of $L$-ascorbic acid, gallic acid and rutin standard solutions working in the same experimental conditions. Scavenging capacity in percent (SC\%) was calculated in following way, according to the equation:

$\mathrm{SC} \%=100-\left[\left(\mathrm{Abs}_{\text {sample }}-\mathrm{Abs}_{\text {blank }}\right) \times 100 / \mathrm{Abs}_{\text {control }}\right.$

where $\mathrm{Abs}_{\text {sample }}$ is the absorbance of the test compound and $\mathrm{Abs}_{\text {control }}$ is the absorbance of the control reaction (containing all reagents except the test compound). SC\% was plotted against sample concentration, and a linear regression curve was established in order to calculate the $\mathrm{SC}_{50}$. Tests were carried out in triplicate. Correlation coefficients were optimised.

\section{Determination of total polyphenol content}

The crude extract and the fractions ( $0.5 \mathrm{~g}$ of each) were dissolved in $10 \mathrm{~mL}$ of ethanol and the volume adjusted to $100 \mathrm{~mL}$ with water. An aliquot of $3 \mathrm{~mL}$ of each solution was dissolved in $100 \mathrm{~mL}$ of water. Final concentration of each fraction was $0.15 \mathrm{mg} \mathrm{mL}^{-1}$. The total polyphenol concentration in crude extract and fractions was measured spectrophotometrically as described by modified Folin-Ciocalteau method. ${ }^{7}$ Briefly, $0.5 \mathrm{~mL}$ of $2 \mathrm{~N}$ Folin-Ciocalteau was added to a 1 $\mathrm{mL}$ of each sample $\left(0.15 \mathrm{mg} \mathrm{mL}^{-1}\right)$, and this mixture was allowed to stand for $5 \mathrm{~min}$ before the addition of $2 \mathrm{~mL}$ of $20 \% \mathrm{Na}_{2} \mathrm{CO}_{3}$. The solution was then allowed to stand for $10 \mathrm{~min}$ before reading at 730 $\mathrm{nm}$ in a spectrophotometer. The estimation of phenolic compounds in the crude extract and fractions was carried out in triplicate. The total polyphenol content was expressed as milligram equivalents of pyrogallic acid per gram of dry fraction.

\section{Antimicrobial screening}

Crude extract and fractions were individually tested against Candida albicans ATCC 28367, Candida glabrata (clinical isolate), Saccharomyces cerevisiae ATCC 28952, Staphylococcus aureus ATCC 25923 Bacillus subtilis ATCC 6633, Pseudomonas aeruginosa ATCC 27853, Escherichia coli ATCC 2792 and the algae Prototheca zopfii (clinical isolate). Bacterial strains were cultured overnight at 37 ${ }^{\circ} \mathrm{C}$ in Mueller-Hinton Agar (MHA). Yeasts were cultured overnight at $30{ }^{\circ} \mathrm{C}$ in Sabouraud dextrose agar.

\section{Broth microdilution method for MIC determination}

The MICs were determined by the broth microdilution method according to Clinical and Laboratory Standards Institute (formerly NCCLS). ${ }^{8}$ Tests were performed in duplicate. Eight different dilutions of each fraction $(4000,2000,1000,500,250,125,62.5$ and 31.25 $\left.\mu \mathrm{g} \mathrm{mL}^{-1}\right)$ in DMSO were prepared. Crude extract was tested at 2500, $1.250,625,312.5,156.25,78.125$, and $39.06 \mu \mathrm{g} \mathrm{mL}^{-1}$ ) in DMSO. Bacteria were inoculated into Mueller-Hinton agar and, after overnight growth; four or five colonies were directly suspended in saline solution so that the turbidity matched the turbidity of the McFarland standard $\left(\approx 10^{8} \mathrm{cfu} / \mathrm{mL}\right)$. By further progressive dilutions with the test medium, the required concentrations were obtained. The suspension was diluted by 1:100 in saline followed by a new dilution of 1:20 in Mueller-Hinton broth, resulting in a final inoculum concentration of $5 \times 10^{4} \mathrm{cfu}$ per well. Yeasts like fungi were inoculated into potato dextrose agar. Tests were performed in sterile U-botton 96-well plates. The first column of the plates was reserved for negative control wells (without inoculants) and the last column, for the positive growth control wells (without antimicrobial agents). The plates were incubated at $35{ }^{\circ} \mathrm{C}$ for $24 \mathrm{~h}$ for bacteria and Candida; $72 \mathrm{~h}$ for $S$. cerevisae. Growth or a lack thereof in the antimicrobial agent containing wells was determined by comparing with the growth control, indicated by turbidity. The lowest concentration that completely inhibited visible growth of the organism was recorded as the MIC. Subcultures were made from the clear wells which did not show any growth after incubation during the MIC assays on Muller-Hinton agar for bacteria and Saboraund agar for fungi in order to achieve Minimal Microbicidal Concentration (MMC), Minimal Fungicidal Concentration (MFC) and Minimal Algaecidal Concentration (MAC). The lowest concentrations that yielded no growth after this sub-culturing were taken as the MMC, MFC and MAC. Standard antibiotics (Ampicillin, Imipenem and Cephoperazone) were used to control the sensitivity of the tested bacteria, whereas Fluconazole and Amphotericin B were used as control against the tested fungi and the algae.

\section{Determination of antimicrobial percent activity (A\%), total antimicrobial activity (TAA) and bacterial susceptible index (BSI)}

These parameters were determinate according the equations listed below: ${ }^{9}$

$$
\mathrm{A} \%=\frac{100 \times \text { of susceptible strains to a specific extract }}{\text { Total }^{\circ} \text { of tested strains }}
$$

$\mathrm{TAA}=\underline{\text { quantity of material extracted from } 1 \mathrm{~g} \text { of plant material }}$ MIC

BSI $=\underline{100 \times \text { no. of extracts effective against each bacterial strain }}$ 


\section{Statistical analysis}

The results were expressed as the mean \pm s.d. of at least three independent experiments. $\mathrm{SC}_{50}$ was calculated from the concentration/ effect linear regression lines.

\section{RESULTS AND DISCUSSION}

Large differences could be seem among the crude extract and fractions antimicrobial activities and also among the microorganisms susceptibility (Table 1). The fungi $S$. cerevisiae was the most vulnerable with a susceptible index (BSI) equal to $100 \%$, showing sensibility for the dichlorometane, ethyl acetate and principally, to butanolic fraction. This result is in agreement with the antifungal activity of some isolated products from other Buddleja species reported in literature. ${ }^{4} \mathrm{~S}$. aureus (BSI $=75 \%$ ) was to some extent susceptible to dichloromethane and ethyl acetate fractions whereas not as much to butanolic fraction. Avila et al. ${ }^{3}$ identified the phenylethanoid verbascoside in Buddleja cordata, as an antimicrobial agent against $S$. aureus. Verbascoside was also identified in B. parviflora by Arciniegas et al. ${ }^{3}$ and in B. globosa by Pardo et al. ${ }^{10}$ Various antimicrobial activities have been noted for verbascoside ${ }^{3,10}$ although the results are controversial. ${ }^{11}$ The presence of phenylethanoids in $B$. thyrsoides in our study was inferred by the UV spectra of ethyl acetate and butanolic fractions (both fractions dissolved in $\mathrm{MeOH}$ ) that showed absorption maxima at $c a$ 220, 280 and $330 \mathrm{~nm}$, the characteristic pattern of phenylethanoids derivatives. ${ }^{12}$ Identification of verbascoside was performed by direct comparison with authentic sample of this compound by TLC. It is probable that this compound contribute to the antimicrobial action showed in ethyl acetate and butanolic fractions, mainly in the ethyl acetate fraction. Concerning the dichloromethane fraction, other variety of compounds must be responsible for the antimicrobial activity observed. All tested samples were ineffective against Candida albicans (BSI=0), whereas the ethyl acetate fraction showed a weak antifungal activity (MIC and MFC at $\left.1000 \mu \mathrm{g} \mathrm{mL}^{-1}\right)$ against $C$. glabrata $(\mathrm{BSI}=50 \%)$. Concerning the Gram-negative bacteria, E. coli $(\mathrm{BSI}=0)$ was resistant to all tested samples, while against $P$. aeruginosa $(\mathrm{BSI}=50 \%$ ), dichloromethane and ethyl acetate fractions showed a weak activity only at the highest concentration tested. These results were to some extent expected, because beside the efflux pumps, Gram-negative bacteria presents some other characteristic particularities in their outer membrane like the polysaccharides that contributes to cell surface properties, such as membrane permeability and antibiotic susceptibility. ${ }^{13}$
Only ethyl acetate fraction showed a weak action against Prototheca zopfii (BSI= 25\%) but at $2000 \mu \mathrm{g} \mathrm{mL}^{-1}$. This pathogen is difficult to eradicate, there is no standard treatment protocol and this algae may exhibit importance in immunocompromised patients, i.e. AIDS, cancer or patients under immunossupressive therapy. ${ }^{14}$ To our knowledge, this is the first assay involving this plant and the algae Prototheca zopfii.

Percentual activity and total antimicrobial activity are very useful tools which may help to choose the better plant, extract or fraction to be study in deep. Percentual activity followed the subsequently decreasing order: dichloromethane and ethyl acetate fractions (62.5\%), crude extract and butanolic fraction $(25 \%)$. Total antimicrobial activity (TAA) indicate the largest volume to which biologically active compounds in $1 \mathrm{~g}$ of plant material can be diluted and still inhibits the growth of bacteria. ${ }^{9}$ Butanolic fraction showed TAA of $848 \mathrm{~mL} \mathrm{~g}^{-1}$ against $S$. cerevisae, indicative that the inhibitory compounds of this fraction could be diluted in $848 \mathrm{~mL}$ of solvent and even provoke the inhibition of this fungus. In the same line, dichloromethane fraction exhibit TAA of $249 \mathrm{~mL} \mathrm{~g}^{-1}$, and ethyl acetate showed TAA of 120 $\mathrm{mL} \mathrm{g}^{-1}$ against $S$. cerevisae. In respect to $S$. aureus, the highest TAA were obtained from dichloromethane (TAA $=124.4 \mathrm{~mL} \mathrm{~g}^{-1}$ ) and ethyl acetate $\left(\mathrm{TAA}=62.2 \mathrm{~mL} \mathrm{~g}^{-1}\right)$ fractions

Partition between immiscible solvents is an adequate approach for the preliminary separation of complex plant matrices because this procedure permits discrimination between polar and non-polar fractions activities. The importance of a preliminary fractionation could be clearly seeing in the case of $S$. cerevisae, $S$. aureus, B. subtilis and $C$. glabrata, through the comparison between crude extract and fractionated extract activities against these microrganisms (Table $1)$. It is mainly probable that the low concentration of the active(s) compounds may prejudice their activity detection in crude extracts. In this study, dichlorometane and ethyl acetate fractions were found to be more effective than the crude extract and butanolic fraction against all the microrganisms tested, however, butanolic fraction demonstrated the highest antifungal activity.

The free radical scavenging capacity of the crude extract and fractions was assessed by the decolouration of the ethanolic solution of DPPH. In the presence of an active radical scavenger, the absorption vanishes and the resulting decolourization is stoichiometric at a selected range with respect to the degree of reduction. Ethanolic solutions of DPPH served as control and three calibration curves made with $L$-ascorbic acid, gallic acid and rutin were used to compare the activities, as positive controls, since those standards antioxidant

Table 1. Minimum inhibitory concentration (MIC), minimum microbicidal concentration (MMC), minimal fungicidal concentration (MFC) and minimal algaecidal concentration (MAC) for crude extract and fractions of Buddleja thyrsoides leaves. Values are expressed in $\mu \mathrm{g} \mathrm{mL}^{1}$

\begin{tabular}{|c|c|c|c|c|c|c|c|c|c|}
\hline & $\begin{array}{c}\text { Crude } \\
\text { extract } \\
\text { MIC }\end{array}$ & $\begin{array}{l}\text { Crude extract } \\
\text { MMC or } \\
\text { MFC }\end{array}$ & $\begin{array}{c}\mathrm{CH}_{2} \mathrm{Cl}_{2} \\
\mathrm{MIC}\end{array}$ & $\begin{array}{c}\mathrm{CH}_{2} \mathrm{Cl}_{2} \\
\mathrm{MMC} \text { or } \\
\mathrm{MFC}\end{array}$ & $\begin{array}{c}\text { AcOet } \\
\text { MIC }\end{array}$ & $\begin{array}{l}\text { AcOet } \\
\text { MMC or } \\
\text { MFC }\end{array}$ & $\begin{array}{c}\mathrm{BuOH} \\
\mathrm{MIC}\end{array}$ & $\begin{array}{c}\mathrm{BuOH} \\
\mathrm{MMC} \text { or } \\
\mathrm{MFC}\end{array}$ & $\begin{array}{l}\text { Control } \\
\mu \mathrm{g} \mathrm{mL} \mathrm{mL}^{-1}\end{array}$ \\
\hline E. coli & $>2500$ & $*$ & $>4000$ & * & $>4000$ & $*$ & $>4000$ & * & Amp 8.0 \\
\hline P. aeruginosa & $>2500$ & $*$ & 4000 & 4000 & 4000 & 4000 & $>4000$ & $*$ & Cef. 16.0 \\
\hline S. aureus & $>2500$ & $*$ & 250 & 500 & 500 & 500 & 2000 & 2000 & Amp 2.0 \\
\hline B. subtilis & 2500 & 2500 & 1000 & $*$ & $>4000$ & $*$ & $>4000$ & $*$ & Imi 0.06 \\
\hline C. albicans & $>1250$ & $*$ & $>2000$ & $*$ & $>2000$ & $*$ & $>2000$ & $*$ & Flu 16 \\
\hline C. glabrata & $>1250$ & * & 2000 & $>2000$ & 1000 & 1000 & $>2000$ & $*$ & Flu 32 \\
\hline S. cerevisae & 1250 & 1250 & 125 & 125 & 250 & 250 & 62.5 & 62.5 & Flu 2.0 \\
\hline P. zopfii & $>1250$ & $*$ & $>2000$ & $*$ & 2000 & $>2000$ & $>2000$ & $*$ & Amp 0.5 \\
\hline
\end{tabular}

$\mathrm{Amp}=$ ampicillin, $\mathrm{Ceph}=$ cephoperazone, $\mathrm{Imi}=$ imipenem, Flu = fluconazole, $\mathrm{Amph}=$ amphotericin $\mathrm{B} . *$ not tested because the MIC was not determinate 
Table 2. Total phenolic contents and $\mathrm{SC}_{50}$ determined in crude extract and fractions of Buddleja thyrsoides leaves

\begin{tabular}{lcc}
\hline Fractions & $\mathrm{mg} \mathrm{g}^{-1} \mathrm{DF}^{1}$ & ${ }^{2} \mathrm{SC}_{50} \mu \mathrm{g} \mathrm{mL}^{-1}$ \\
\hline Ethyl acetate & $438.4 \pm 0.3^{\mathrm{a}}$ & $137.70 \pm 8.5^{\mathrm{a}, \mathrm{b}}$ \\
Dichlorometane & $298.6 \pm 1.0^{\mathrm{b}}$ & $146.89 \pm 9.0^{\mathrm{a}}$ \\
n-Butanol & $231.87 \pm 5.9^{\mathrm{c}}$ & $165.71 \pm 3.2^{\mathrm{a}}$ \\
Crude extract & $214.07 \pm 3.6^{\mathrm{d}}$ & $186.04 \pm 10.8^{\mathrm{b}}$ \\
\hline
\end{tabular}

Measurements were averaged, and results are given as mean \pm standard deviation. ${ }^{1}$ Concentration of phenolic compounds expressed as milligram equivalents of pyrogallic acid per gram of dry fraction (DF). ${ }^{2}$ Concentration required to inhibit radical formation by $50 \%$. ${ }^{\mathrm{a}-\mathrm{d}}$ Different superscripted letters indicate statistical differences in each column $(\mathrm{p}<0.05)$.

activities are well established. DPPH scavenging activity has been largely used as a quick and reliable parameter to assess the in vitro general antioxidant of plant extracts, which has been assigned mainly to phenolic compounds. $L$-ascorbic acid showed $\mathrm{SC}_{50}=6.31 \pm 0.08$ $\mu \mathrm{g} \mathrm{mL} \mathrm{m}^{-1}(\mathrm{y}=2.0805 \mathrm{x}+36.898, \mathrm{r}=0.894)$ and $\mathrm{SC}=97.1 \%$ at 31.25 $\mu \mathrm{g} \mathrm{mL} \mathrm{m}^{-1}$, and the rutin present $\mathrm{SC}_{50}=19.86 \pm 0.05(\mathrm{y}=2.2632 \mathrm{x}+$ $5.0494, \mathrm{r}=0.958$ ) and $\mathrm{SC}=78.82 \%$ at $31.25 \mu \mathrm{g} \mathrm{mL} \mathrm{m}^{-1}$. The $\mathrm{SC}_{50}$ value for gallic acid wasn't calculated by linear regression because the inhibition presented for all the concentrations used in the curve were above $92 \%$. Thus, $\mathrm{SC}_{50}$ for gallic acid was estimated by rule of three in $4.24 \pm 0.02 \mu \mathrm{g} \mathrm{mL}^{-1}$. Ethyl acetate fraction exhibit $\mathrm{SC}_{50}=137.70 \pm$ $8.5 \mu \mathrm{g} \mathrm{mL}-1(\mathrm{y}=0.2947 \mathrm{x}+9.5557, \mathrm{r}=0.994)$ and $\mathrm{SC}=81.43 \%$, the dichloromethane fraction showed $\mathrm{SC}_{50}=146.89 \pm 9.0 \mu \mathrm{g} \mathrm{mL}^{-1}(\mathrm{y}=$ $0.2982 \mathrm{x}+6.3122, \mathrm{r}=0.991)$ and $\mathrm{SC}=79.26 \%$, the butanolic fraction revealed $\mathrm{SC}_{50}=165.71 \pm 3.2 \mu \mathrm{g} \mathrm{mL}^{-1}(\mathrm{y}=0.283 \mathrm{x}+3.1087, \mathrm{r}=0.992)$ with $\mathrm{SC}=74.03 \%$, and crude extract $\mathrm{SC}_{50}=186.04 \pm 10.8 \mu \mathrm{g} \mathrm{mL}$ $(\mathrm{y}=0.2343+6.5057 \mathrm{r}=0.938)$ and $\mathrm{SC}<60 \%$ at $250 \mu \mathrm{g} \mathrm{mL}^{-1}$, all in a dose-dependent manner. The better antioxidant activity exhibited by ethyl acetate fraction may be due for the high presence of phenolic compounds in this fraction. Similar findings were related by Silva et al., ${ }^{15}$ analyzing different fractions of Sida galheirensis.

Total polyphenol contents were determined by the Folin-Ciocalteau method using pyrogallic acid as standard. The equation obtained for standard curve of pyrogallic acid in the range of $0.005-0.030 \mathrm{mg}$ $\mathrm{mL}^{-1}$ was $\mathrm{y}=34.443 \mathrm{x}-0.0942(\mathrm{r}=0.994)$. Total polyphenol contents expressed as pyrogallic acid equivalents varied from $214.07 \pm 3.6$ to $438.4 \pm 0.3 \mathrm{mg} \mathrm{g}^{-1}$ dry fraction (Table 2). Polyphenol contents were higher in the ethyl acetate and dichloromethane fractions, followed by butanolic fraction and crude extract. Many researches describe a positive correlation between phenolic contents and antioxidant activity $^{7,16}$ with DPPH and Folin-Ciocalteau as analytical methods. In the present study, looking at the possibly correlations between the amount of phenolic compounds of the extract and fractions and the antioxidant activities of these samples, a positive correlation could be established $(\mathrm{r}=0.857, \mathrm{p}<0.01)$. Therefore, ethyl acetate and dichloromethane fractions, that furnish the highest phenolic content, were the same fractions that exhibited better scavenger activity in the DPPH assay and butanolic and crude extract fractions that afforded the lowest phenolic contents showed also the smaller scavenging activity.

The present study clearly demonstrated, for the first time, $B$. thyrsoides has a biological activity as a free radicals scavenger by the DPPH method and confirmed the existence of a positive correlation with its phenolic contents. Ethyl acetate and dichloromethane fractions from $B$. thyrsoides were the most effective agents for scavenging free radicals in the DPPH method and presented highest phenolic contents. As pointed out before, ${ }^{3}$ the antioxidant and antimicrobial activities in $B$. thyrsoides may in part be due to the presence of phenylethanoids which were support by UV measurements. ${ }^{12}$ A clear antimicrobial activity was evidenced when the highest polar butanolic fraction was added to $S$. cerevisae cultures, and when the less polar fraction dichloromethane was tested against $S$. aureus. Because lethality may be the end result of a variety of toxic mechanisms, a battery of in vitro tests with different endpoints will be more predictive than was the single assays presently obtained, since they were restricted to in vitro acute lethality tests. Especially due to the fact that assays were carried out with crude extract and partitions, a wide variety of compounds with different mechanisms of action were present must be purified and tested at different combinations.

It may be concluded $B$. thyrsoides biological activities is due to a wide variety of compounds with different mechanisms of action, warranting a further purification and characterization of the actives principles from the dichloromethane, ethyl acetate and butanolic fractions. Certainly it will provide a better understanding of B. thyrsoides antimicrobial and antioxidant mechanisms.

\section{ACKNOWLEDGEMENTS}

The authors are grateful to FIPE/CCS/UFSM and Programa de Pós-Graduação em Ciências Farmacêuticas (Universidade Federal de Santa Maria) for financial support to the project. The authors are in debt with Dr. M. R. Farias (Universidade Federal Santa Catarina) for provide us a sample of verbascoside.

\section{REFERENCES}

1. Mabberley, D. J. In The plant-book; Cambridge University Press: Cambridge, 1987, p. 707; Leeuwenberg, A. J. M.; Landbouwhogeschool Wegeningen 1979, 79, 1.

2. Houghton, P. J.; J. Ethnopharmacol. 1984, 11, 293; Houghton, P. J.; Manby, J.; J. Ethnopharmacol. 1985, 13, 89.

3. Avila, J. G.; Liverant, J. G.; Martinez, A.; Martinez, G.; Munoz, J. L.; Arciniegas, A.; Vivar, A. R.; J. Ethnopharmacol.1999, 66, 75; Arciniegas, A.; Avendaño, A.; Pérez Castorena, A. L.; Vivar, A. R.; Biochem. Syst. Ecol. 1997, 25, 185; Houghton, P. J.; Hikino, H.; Planta Med. 1989, 55, 123; Mensah, A. Y.; Houghton, P. J.; Bloonfield, S.; Vlietinck, A.; Vander Berghe, D.;J. Nat. Prod. 2000, 63, 1210; Houghton, P. J.; Abrahan, Y.; Mensah, A. Y.; Yong-Hong, L.; Phytochemistry 2003, 64, 385; Emam, A. M.; Moussa, A. M.; Faure, R.; Favel, A.; Delmas, F.; Elias, R.; Balansara, G.; Planta Med. 1996, 62, 92.

4. Mensah, A. Y.; Sampson, J.; Houghton, J. P.; Hylands, J. P.; Westbrook, J.; Dunn, M.; Hughes, M. A.; Cherry, G.W.; J. Ethnopharmacol. 2001, 77, 219; Houghton, P. J.; Hylands, P. J.; Mensah, A. Y.; Hensel, A.; Deters, A. M.; J. Ethnopharmacol. 2005, 100, 100.

5. Plantas brasileiras. Available in www.brazilianplants.com/br/search.cfm, accessed in September 2007; Mahlke, J. D.; Zanetti, G. D.; Machado, M. M.; Manfron, M. P.; Athayde, M. L.; Lat. Am. J. Pharm. 2008, 27, 505.

6. Choi, C. W.; Kim, S. C.; Hwang, S. S.; Choi, B. K.; Ahn, H. J.; Lee, M. Y.; Park, S. H.; Kim, S. K.; Plant Sci. 2002, 163, 1161.

7. Chandra, S.; Mejia, E. G.; J. Agric. Food Chem. 2004, 52, 3583; Verza, S. G.; Kreinecker, M. T.; Reis, V.; Henriques, A. T.; Ortega, G. G.; Quim. Nova 2007, 30, 815.

8. National Committee for Clinical Laboratory Standards (NCCLS); Reference method for broth dilution antifungal susceptibility testing of yeasts. Approved standard M27-A2, 2002a; National Committee for Clinical Laboratory Standards (NCCLS); Methods for dilution antimicrobial susceptibility tests for bacteria that grow aerobically. Approved standard; document M7-A5, $5^{\text {th }}$ ed., 2002b, Wayne, PA. 
9. Ellof, J. N.; Phytomedicine 2004, 11, 370; Rangasamy, O.; Raoelison, G.; Rakotoniriana, F. E.; Cheuk, K.; Urverg-Ratsimamanga, S.; QuetinLeclercq, J.; Gurib-Fakim, A.; Subratty, A. H.;J. Ethnopharmacol. 2007, 109, 331 .

10. Pardo, F.; Perich, F.; Villaroel, L.; Torres, R.; J. Ethnopharmacol. 1993, 39, 221; Didry, N.; Seidel, V.; Dubreuil, L.; Tillequin, F.; Bailleul, F.; J. Ethnopharmacol. 1999, 67, 197; Nazemiyeh, H.; Mukhlesur Rahman, M.; Gibbons, S.; Nahar, L.; Delazar, A.; Ghahramani, M-A.; Talebpour, A-H.; Sarker, S. D.; J. Nat. Med. 2008 62, 91; Backhouse, N.; Rosales, L.; Apablaza, C.; Goity, L.; Erazo, S.; Negrete, R.; Theodoluz, C.; Rodrigues, J.; Delporte, C.; Ethnopharmacol. 2008, 116, 263.

11. Obied, H. K.; Bedgood Jr., D. R.; Prenzler, P. D.; Robards, K.; Food Chem. Toxicol. 2007, 45, 1238.

12. Li, L.; Tsao, R.; Liu, Z.; Liu, S.; Yang, R.; Young, J. C.; Zhu, H.; Deng, Z.; Xie, M.; Fu, Z.; J. Chromatogr., A 2005, 1063, 161; Gormann, R.; Kaloga, M.; Ferreira, D.; Marais, J. P. J.; Kolodziej, H.; Phytochemistry 2006, 67, 805; Martin, F.; Hay, A.; Corno, L.; Gupta, M. P.; Hostettmann, K.; Phytochemistry 2007, 68, 1307.
13. Charbonnier, F.; Kohler, T.; Pechere, J. C.; Ducruix, A.; Protein Expression and Purification 2001, 23, 121; Yokota, S.; Fujii, N.; Comp. Immunol. Microbiol. Infec. Dis. 2007, 30, 97.

14. Lass-Flörl, C.; Fille, M.; Gunsilius, E.; Gastl, G.; D. Nachbaur, D.; J. Clin. Microbiol. 2004, 42, 4907; Sidrim, J. J. C.; Rocha, M. F. G.; Câmara, L. M. C.; Brilhante, R. S. N.; Diógenes, M. J. N.; Oliveira, A. M. A.; Clinical Microbiology Newsletter 2003, 25, 69.

15. Silva, D. A.; Silva, T. M. S.; Lins, A. C. S.; Costa, D. A.; Cavalcante, J. M. S.; Matias, W. N.; Souza, M. F. V.; Braz Filho, R.; Quim. Nova 2006, 29,250 .

16. Shyamala, B. N.; Gupta, S.; Lakshmi, A.; Prakash, J.; Innovative Food Science \& Emerging Technologies 2005, 6, 239; Sousa, C. M. M.; Rocha e Silva, H.; Vieira-Jr., G. M.; Ayres, M. C. C.; da Costa, C. L. S.; Araújo, D. S.; Cavalcante, L. C. D.; Barros, E. D. S.; Araújo, P. B. M.; Brandão, M. S.; Chaves, M. H. ; Quim. Nova 2007, 30, 351. 